\title{
A imaginação como recurso heurístico na construção do conhecimento científico e algumas implicações para o ensino de ciências ${ }^{+*}$
}

João Otavio Garcia ${ }^{1}$

Mestrando no Programa de Pós-Graduação em Educação Científica

e Tecnológica (PPGECT) - Universidade Federal de Santa Catarina

Florianópolis - SC

\section{Resumo}

Discute-se, neste artigo, que a imaginação configura-se como um recurso heurístico ativo nos processos sociais e históricos de construção do conhecimento científico, podendo ser utilizada, por exemplo, no desenvolvimento de experimentos mentais. Tais experimentos servem como ferramentas que contribuem para o desenvolvimento científico, principalmente ao serem empregados, considerando-se a imaginação como recurso que guiará as possíveis alterações que uma conjectura poderá sofrer, ao longo de seu desenvolvimento. Explora-se, ainda, a importância de tratar o papel da imaginação na atividade científica no ensino de ciências, utilizando um episódio histórico específico - alcunhado de "O prato de Feynman" - de modo a considerar esta uma forma profícua de dirimir a concepção empiricista pura da atividade científica, tencionando fomentar um ensino em e sobre ciência.

Palavras-chave: Imaginação e Ciência; Natureza da Ciência; Heurística; Ensino de Ciências.

\begin{abstract}
In this paper, it is argued that imagination is configured as an active heuristic resource in the social and historical construction of scientific
\end{abstract}

\footnotetext{
${ }^{+}$The imagination as heuristic resource in the construction of scientific knowledge and some implications for Science Teaching

* Recebido: novembro de 2018. Aceito: julho de 2019.

${ }^{1}$ E-mails: joaoppgect@gmail.com
} 
knowledge processes and that can be used, for example, in development mental experiments. These experiments serve as tools that contribute to the scientific development, especially when they are used considering the imagination as a resource that will guide the possible changes that a conjecture may suffer, throughout its development. It is also explored the importance of treating the role of imagination in scientific activity in science teaching using a specific historical episode-called "The Feynman Dish" - in order to consider this a useful way to minimize the empiricist conception scientific activity, intending to foster teaching in and about science.

Keywords: Imagination and Science; Nature of Science; Heuristic; Science Teaching.

\section{Introdução}

A fotografia de um homem idoso, com cabelos grisalhos e desgrenhados, olhos esgazeados e língua de fora, possivelmente configurou-se como uma das imagens mais famosas da cultura popular, que pôde ter contribuído para uma a construção de caricaturas da pessoa por trás dela, popularizando-a, de certa forma. A fotografia, capturada pelas lentes ágeis de Arthur Sasse (1908-1975), registra um dos mais influentes e polêmicos cientistas do século XX. Albert Einstein (1879-1955) foi um físico teórico alemão laureado com o Prêmio Nobel de 1921, famoso principalmente por seus estudos sobre o efeito fotoelétrico e pelas teorias da Relatividade Restrita e Relatividade Geral.

Além do adjetivo de influente, dadas suas contribuições à Física, Einstein pode ser considerado polêmico por afirmações que fazia à imprensa, como em uma entrevista concedida ao poeta alemão George Sylvester Viereck (1884-1962), acerca de suas opiniões relacionadas a temas diversos como política, religião e ciência. Quando Viereck pergunta a Einstein como este havia chegado às suas ideias, Einstein audazmente responde; "Sou artista o suficiente para inspirar-me livremente na minha imaginação. A imaginação é mais importante que o conhecimento. O conhecimento é limitado. A imaginação abrange o mundo inteiro" (ISAACSON, 2007, p. 396). Entretanto, ainda que Einstein não tenha buscado promover juízo de valor entre imaginação e conhecimento, acabou por destacar certa flexibilidade ou liberdade àquela no desenvolvimento científico.

Em relação a estudos envolvendo concepções filosóficas acerca do desenvolvimento científico, uma linha de investigação denominada Natureza da Ciência (NdC) já vem sendo discutida por diversos pesquisadores, como Matthews (1995), Harres (1999), Köhnlein e Peduzzi (2005), Peduzzi e Silveira (2006), Oki e Moradillo (2008), Arthury (2010), Moura (2014), Damasio e Peduzzi (2017) e Peduzzi e Raicik (2019). Tal linha é considerada profícua, principalmente, para problematizar concepções filosóficas sobre a atividade científica no 
ensino de ciências, seja no âmbito da educação básica, seja no ensino superior. Discussões como: a não-neutralidade da observação; a insustentabilidade do empiricismo puro no desenvolvimento de conjecturas; um ensino tanto de quanto sobre a ciência; a importância da abordagem didática da história e a filosofia da ciência, principalmente sob a óptica da evolução de seus conceitos, compõem alguns dos temas investigados.

$\mathrm{Na}$ busca de discutir certas concepções acerca das insustentabilidades do empiricismo puro na ciência, torna-se interessante destacar a importância dos experimentos mentais ${ }^{2}$, os quais se têm tornado ferramenta importante, principalmente nos constructos da Física Teórica. Nessa abordagem, atribui-se certa flexibilidade aos experimentos mentais, na possibilidade, por exemplo, de serem realizados previamente, podendo servir “(...) como um importante recurso heurístico na proposição, discussão e estabelecimento de novas ideias, conceitos e teorias" (PEDUZZI; RAICIK, 2019, p.15). Nessa perspectiva, a imaginação pode ser considerada como um recurso heurístico, se pensarmos no seu uso em termos tanto de desenvolvimento da ciência quanto de experimentos mentais. Isso não significa que ambos sejam idênticos, pois podemos usar a imaginação sem necessariamente desenvolver um experimento mental; jamais o contrário.

Assim, este trabalho tenciona discutir um episódio da história da Física em que a imaginação contribuiu para o desenvolvimento da ciência atuando como um recurso heurístico, de forma inspiradora e serendíptica. Ou seja, não será discutido amplamente aqui o uso de experimentos mentais, seja na construção do conhecimento científico, seja no ensino de Física. Entretanto, cabe destacar que os experimentos mentais “(...) permitem que aqueles estudantes mais inseguros adquiram com a mediação do professor, confiança para perseguirem na discussão, na busca de solução e compreensão do fenômeno" (KIOURANIS; SOUZA; SANTIN FILHO, 2010, p. 1507-8).

Nessa perspectiva, ainda que este artigo não proponha nenhuma atividade didática ou material envolvendo experimentos mentais e a imaginação no ensino de Física, pode-se considerar que destacar a imaginação como um recurso heurístico, é um passo inicial para propostas desta natureza. Este destaque pode ser considerado um passo inicial, por sinalizar a importância da imaginação nos processos de construção de conhecimento científico, buscando tratar tais processos de forma menos rigidamente padronizada. A construção de conhecimento científico, nesse sentido, pode ser discutida em sala de aula de forma mais flexível, tratando com os alunos que os cientistas podem utilizar diversas ferramentas nesta construção. Além disso, destacar a importância da imaginação na construção de conhecimento científico com estudantes contribui para afastarmo-nos das concepções puramente empiricistas da atividade científica, justamente por tentar romper com a imagem do cientista como um "gênio isolado" do resto da sociedade.

2 O termo "Experimentos mentais" (ou Gedankenexperiments) foi cunhado pelo físico alemão Ernst Mach (1838-1916). 
Dessa forma, ainda que este artigo não esgote as discussões sobre experimentos mentais e ensino de Física, oferece uma breve discussão sobre estes enquanto ferramenta que, utilizando a imaginação como recurso heurístico, contribui para o desenvolvimento científico. Desse modo, será apresentado sucintamente um episódio da história da Física, por meio de discussões que envolvam o destaque à imaginação na ciência, buscando destacar a importância de aspectos que contrariam a concepção rígida e puramente empiricista de ciência, centralizando-se nos processos sociais e históricos de construção do conhecimento científico.

\section{A imaginação e a falácia da observação como base neutra na atividade científica}

Einstein ter considerado a imaginação como um dos lastros de seu trabalho como cientista pode configurar-se como parte de uma concepção filosófica que destaca a importância de compreender o cientista como personagem cujas atividades não são neutras, ressaltando aspectos idiossincráticos e volitivos e como estes influenciam seu trabalho.

Destacar essa importância acentua o caráter não-neutro das atividades dos cientistas nos processos sociais e históricos de construção coletiva de conhecimento científico e vilipendiam a concepção - herdada do empiricismo ingênuo - de uma ciência puramente objetiva. Dessa forma, destaca-se “(...) o relato indutivista ingênuo da ciência como sendo muito errado e perigosamente enganador" (CHALMERS, 1993, p.29), principalmente porque este relato carrega, dentre outros aspectos, a concepção da observação como uma base neutra e segura na qual o cientista "chegaria à verdade" por meio da indução. Nessa perspectiva, compreender que "provamos a verdade" das teorias científicas é uma forma distorcida de discutir a $\mathrm{NdC}$, considerando que “(...) por mais corroborada que uma teoria seja, não está livre de crítica e no futuro poderá se mostrar problemática e poderá ser substituída por outra" (SILVEIRA, 1996, p. 202). Entretanto, isto não significa advogar por uma ciência que não seja objetiva. Trata-se de compreender que, dada a complexidade da atividade científica, esta não pode ser reduzida à busca por uma suposta base neutra para se produzir conhecimento somente por meio da indução ou da observação sistêmica.

Cabe destacar que não se defende aqui que não existam elementos objetivos no desenvolvimento científico, tampouco que seja possível separar em parcelas a atuação do sujeito e do objeto de estudo neste processo. No entanto, é justamente tratando com importância o papel da imaginação que se torna possível compreender que a complexidade da atividade científica extrapola a simples sucessão de etapas segmentadas e infalíveis que se constituem por uma sequência rígida de acertos, feita por sujeitos neutros.

A insustentabilidade de se considerar a observação como base neutra e segura pela qual supostamente adentraríamos as urdiduras da realidade objetiva acarreta no problema de cisar observação e interpretação. Esta cisão torna-se problemática, considerando que, além de observação e interpretação nunca se manifestarem separadamente, “(...) é inconcebível manifestar-se qualquer das partes sem a outra" (HANSON, 1975, p. 127). No exemplo de Einstein, este estaria contrariando a concepção empiricista ingênua da atividade científica, identifican- 
do um experimento mental que se constitui pelo uso da imaginação, como ferramenta necessária à construção de conhecimento científico. Assim, imaginar e interpretar estariam entrelaçados e presentes nesse processo de construção, não sendo manifestados separadamente.

Nessa perspectiva, compreender a ciência como um corpo de conhecimentos puramente objetivo, na qual, através de observações neutras e por meio de um método indutivo "chegaríamos à verdade" escondida nos recônditos da natureza, é uma forma perniciosa de compreendê-la, de estudá-la e de ensiná-la. Cabe, portanto, questionarmo-nos a respeito da existência de episódios na história da ciência nos quais aspectos como a imaginação, por exemplo, são considerados importantes. Tal consideração pode ser destacada tanto no desenvolvimento de conjecturas quanto em relação aos valores atribuídos à imaginação e ao conhecimento na dinâmica da atividade científica.

O apelo à suposta segurança fornecida pela observação está relacionado a uma concepção de construção do conhecimento científico arraigada univocamente aos processos sensoriais humanos, ou seja, aos órgãos dos sentidos (HANSON, 1975). O uso da imaginação (nesse caso específico, relacionado ao desenvolvimento de experimentos mentais) é uma forma de manifestar a importância de considerar a ciência uma atividade humana, considerando tais experimentos como ferramentas que contribuem para o desenvolvimento científico e não como algo que, de forma solilóquia, o cientista utiliza arbitrariamente. Dessa forma, Hanson (1975) trata da não-neutralidade das observações:

Onde erram as pessoas que referem suas observações? Erram, habitualmente, ao exagerarem as descrições do que encontraram e não por haverem recebido do mundo exterior sinais-sensórios errados. As pessoas dirão estar vendo água - quando, em verdade, se trata de um ácido fraco, onde a madeira mergulhada se destrói. Dirão estar vendo gelo - quando, em verdade, se trata de deutério congelado, porque não flutua na água. Dirão estar vendo através de óculos comuns - quando se trata de um vidro polaroide, pois, girado de 90, se torna opaco (HANSON, 1975, p. 128).

Faz-se importante destacar, entretanto, que não significa que, se as observações não são neutras, o uso da imaginação estabeleceria tal neutralidade no desenvolvimento científico.

Ainda na perspectiva da não-neutralidade da observação, Matthews (1995) utiliza um exemplo da Física galileana, que contribui para essa discussão, a partir de uma situação onde o professor buscaria ensinar a isocronia de um pêndulo:

(...) ninguém tem dúvidas de que um pêndulo qualquer, de qualquer comprimento e massa, se posto em movimento, logo irá parar. Isto é uma prova conclusiva de que pêndulos não são isocrônicos: o período da última oscilação não é o mesmo da primeira; um pêndulo realmente isocrônico oscilaria indefinidamente. Como podemos conciliar a lei com a observação? Normalmente se diz: Esqueça o que vê e aprenda a lei. O que é uma forma mais sofisticada de se dizer: A ciência não lida com esses tipos de pêndulos que você usa, mas sim com pêndulos ideais para os 
quais não há atrito e pressão e onde o fio não possui peso, etc. Isso satisfaz ao professor de ciências com conhecimento em HFS, mas será que satisfaz ao estudante? (MATTHEWS, 1995, p. 182, grifo meu).

Se o professor de Física discutisse que a ciência "não lida com esses tipos de pêndulos que você usa" não de forma impositiva, mas buscando discutir com seus alunos que, muitas vezes, acabamos por criar uma dicotomia entre o "mundo real" e o "mundo da Física", este professor estaria contribuindo para uma concepção menos distorcida da atividade científica. Tal discussão torna-se pertinente na possibilidade de tratar a imaginação como ferramenta útil para pensar em pêndulos isocrônicos, em quedas livres, superfícies livres de atrito e diversas situações ideais, de modo que este exercício é importante no ensino de Física, tanto na educação básica quanto na superior.

A preocupação em atribuir papel importante para a imaginação na construção de conhecimento científico no ensino de ciências pode ser realizada envolvendo aspectos históricos da atividade científica. O professor que trabalha, por exemplo, a evolução dos conceitos da Física, poderia discutir com os alunos o papel da imaginação atuando como um recurso heurístico no desenvolvimento de experimentos mentais ao longo da história da Física, bem como abordar a importância destes para a atividade científica.

Tal preocupação relacionada à importância da imaginação e dos experimentos mentais é destacada desde a antiguidade, não somente na Física moderna e contemporânea (FMC), sendo utilizada como lastro para discutir o papel dos experimentos mentais em um episódio específico. Nesse sentido, tratando, por exemplo, do período aristotélico, os experimentos mentais "permitiram a Aristóteles fundar um edifício filosófico de explicação da natureza cujos alicerces e envergadura se mostrou tão robusto que persistiu até os trabalhos de Galileu e de alguns de seus contemporâneos e antecessores" (KIOURANIS; SOUZA; SANTIN FILHO, 2010, p. 1507-1).

Entretanto, uma vez que se menciona Aristóteles, é necessário contextualizar que não é porque existe a possibilidade de ele ter realizado experimentos mentais que o objetivo seja inferir que o filósofo em questão realizava experimentos não-mentais em situações concretas. Tampouco que ele tenha desenvolvido métodos de experimentação concreta, como destacam Raicik, Peduzzi e Angotti (2018):

Os aristotélicos, por exemplo - e seus ensinamentos que predominaram até a Idade Média e o Renascimento e, inclusive, fundamentaram as primeiras universidades a partir do século XII - buscavam o conhecimento pela dedução de princípios primeiros. A edificação e o desenvolvimento do conhecimento especulativo, contemplativo, de organização empírica e de hierarquização abstrata das coisas não necessitava, de fato, de experimentos (...) o homem sempre teve a oportunidade de fazer observações a respeito da natureza. Contudo, no campo de um empirismo especulativo, essa observação pode ser associada apenas a uma "experiência vivencial"; e isso não constitui indício de algum método mais sistemático para produzir conhecimentos (RAICIK; PEDUZZI; ANGOTTI, 2018, p. 112). 
Os experimentos mentais, assim como outras formas de experimentação, portanto, não devem ser compreendidos de forma univocamente verificacionista. Assim, “(...) é fundamental lembrar que o cientista ainda "prevê" ou, pelo menos, já busca certo resultado experimental, pelo menos no sentido de "resolução de problemas", conceito apresentado inicialmente por Kuhn" (KIOURANIS; SOUZA; SANTIN FILHO, 2010, p. 1507-2). Ou seja, os experimentos mentais também podem ser compreendidos como recursos heurísticos para resolução de problemas, ou para problematizar condições de contorno de um problema que, até determinado momento, ainda não possui solução.

Considerando ainda os experimentos mentais na história da Física, Popper (1972) destaca a sua importância heurística. Popper (1972) ressalta a importância deles tanto na Física clássica, quanto na moderna, enfatizando que: “(...) tornaram-se particularmente importantes no campo da termodinâmica (ciclo de Carnot) e, ultimamente, ficaram mais ou menos em moda, devido a seu uso pela relatividade e pela teoria quântica" (POPPER, 1972, p. 505). Além desse caráter destacado envolvendo a história da Física, Popper (1972) enfatiza, com primazia, a importância desses experimentos mentais no desenvolvimento da argumentação crítica:

Ora, o uso de experimentos imaginários em argumentação crítica é, indiscutivelmente, legítimo; ele equivale a uma tentativa de mostrar que certas possibilidades foram esquecidas pelo autor de uma teoria. Claro está que é igualmente legítimo contestar essas objeções críticas, mostrando, por exemplo, que o experimento imaginário proposto é, em princípio, impossível e que pelo menos nesse caso, não se deixará de considerar possibilidade alguma (POPPER, 1972, p. 506).

Destarte, far-se-á uma breve discussão a partir de um episódio na história da Física no qual a imaginação foi utilizada como um recurso heurístico. Dessa forma, ainda que não se forneça aqui um estudo histórico aprofundado, tal episódio poderia ser estudado profundamente para auxiliar na construção de propostas didáticas em relação às discussões da importância da imaginação atuando como um recurso heurístico no desenvolvimento de experimentos mentais.

\section{A imaginação como recurso heurístico: o prato de Feynman}

Além de Popper (1972), como destacado anteriormente, a heurística também foi discutida por outros filósofos da ciência, como Imre Lakatos (1922-1974). Tratando, por exemplo, a heurística positiva, Lakatos e Musgrave (1979) sugerem que ela pode abarcar modelos que contribuem para simular a realidade. Nesse sentido, a imaginação é um recurso heurístico que, contribuindo para o desenvolvimento de experimentos mentais, por exemplo, atuaria diretamente na heurística positiva do desenvolvimento de um programa de pesquisa. Tal atuação direta auxiliaria o cientista a pensar em possíveis - e no caso da imaginação, menos limitadas - formas e metodologias para aprimorar suas conjecturas ou ainda identificar anomalias. 
No entanto, cabe ressaltar que a heurística positiva sugere o desenvolvimento de modelos explicativos, mas não os determina, tacitamente. Além disso, a imaginação poderia também ser utilizada como recurso heurístico que atuaria diretamente na heurística negativa do programa de pesquisa, pois, frente a possíveis anomalias, os experimentos mentais auxiliariam o cientista a persistir em alguns aspectos do seu programa de pesquisa sem refutá-lo ou declarar o núcleo firme como falso.

Desse modo, um episódio na história da Física, neste caso alcunhado de "O prato de Feynman", serve de exemplo para discutir a imaginação atuando como recurso heurístico no desenvolvimento de um experimento mental. Tal episódio ocorre em uma determinada época da carreira do físico Richard Feynman (1918-1988), na qual ele encontrava-se na Cornell University logo após sua participação no Projeto Manhattan.

Nesse episódio, Feynman (1993) relata estar na lanchonete na Cornell University quando “(...) alguém, que estava passeando por ali, jogou um prato ao ar. Quando o prato subiu, eu o vi chacoalhar e percebi o brasão vermelho de Cornell desenhado no prato, girando" (FEYNMAN, 1993, p. 167). Segundo o próprio Feynman, “(...) estava sem nada para fazer, então comecei a calcular o movimento do prato em rotação” (FEYNMAN 1993, p. 167), quando começou a imaginar a possibilidade de existir alguma explicação para o fenômeno.

Nessa época, a alternativa de Feynman foi buscar divertir-se com a Física sem preocupar-se com a importância (ou aplicabilidade quasi-imediata) das conjecturas que desenvolvesse ou que buscasse, de alguma forma, testar ou manipular. No entanto, cabe ressaltar que esse "brincar com a Física" não deve ser compreendido de forma despretensiosa, uma vez que Feynman atuava na Cornell University e realizava pesquisas com Eletrodinâmica Quântica e não simplesmente passava o dia "se divertindo com a Física". Inclusive, mesmo algumas semanas após este episódio com o prato, Feynman encontrava dificuldades com os cálculos integrais que vinha realizando na tentativa de explicar tal fenômeno (MEHRA, 1996).

O fenômeno percebido por Feynman foi de que o prato oscilava duas vezes mais rápido do que girava ao redor de seu eixo. Apesar de Feynman (1993) discutir a curiosidade que sentiu neste episódio com o prato na cafeteria e relatar que buscou imaginar a forma como o fenômeno ocorria, ele não deu detalhes de como chegou a seus resultados, matematicamente. Com a intenção de dar maior visibilidade a esse fenômeno, Tuleja, Gazovic e Tomori (2007) trabalharam com as equações e produziram uma simulação computacional, por meio da qual se tornou possível visualizar a relação de dois para um (oscilação do prato duas vezes mais rápida que o giro em torno de seu eixo $)^{3}$.

No entanto, mesmo sem realizar aqui os cálculos, apenas manipulando tal simulação, podemos notar esta relação de dois para um, como nas figuras seguintes. Na Fig. 1, está representado o prato com os eixos fixos $\left(x_{1}, x_{2} \mathrm{e} x_{3}\right)$, de modo que estes descreverão a trajetória de

3 Esta simulação, feita em formato de "Executable Jar File" pode ser conferida em <https://aapt.scitation.org/doi/suppl/10.1119/1.2402156>. O arquivo intitulado feynmanplatearchive.jar (651 $\mathrm{KB})$ contém a simulação que pode ser baixada e utilizada variando parâmetros angulares. 
rotação do disco. A oscilação é descrita pelo eixo $\omega$, sendo que, na Fig. 1, o prato ainda não começou a se movimentar. Já na Fig. 2, o prato realizou uma oscilação completa, enquanto apenas a metade de uma rotação. Isso fica claro, se olharmos para a trajetória (em amarelo) descrita por $\omega$ completa, e a trajetória de rotação (em vermelho e azul) apenas metade realizada.

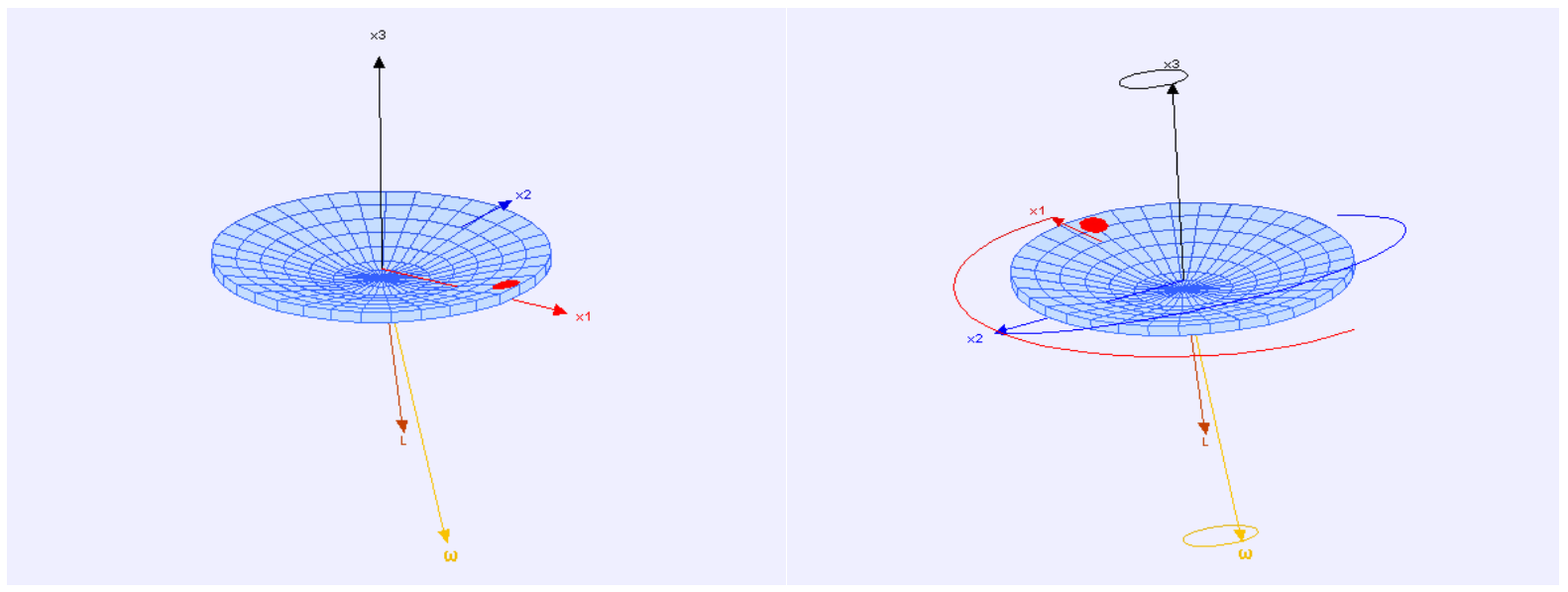

Fig. 1 - Prato na posição inicial.

Fig. 2 - Prato após uma oscilação completa.

Tuleja, Gazovic e Tomori (2007) ainda destacam que o uso da simulação auxiliou na explicação de um fenômeno cuja modelização matemática é complexa, de modo que, para eles, "É interessante ver como os resultados obtidos pela nossa simples análise se comparam aos obtidos pela solução exata" (TULEJA; GAZOVIC; TOMORI, 2007, p. 244). Nessa perspectiva, algo que Feynman teve que imaginar, aliado a todo desenvolvimento matemático que produziu, podemos perceber nitidamente com a simulação. Dessa forma, considera-se que a imaginação atuando como recurso heurístico no desenvolvimento de experimentos mentais é um dos recursos que o cientista pode utilizar no desenvolvimento de conjecturas para, por exemplo, simular mentalmente os efeitos causados alterando parâmetros de forma similar a um experimento concreto.

Considerando novamente a importância de compreender que esses episódios somente são possíveis mediante uma mente preparada, é possível destacar que a forma como Feynman desenvolve a investigação acerca desse fenômeno com o prato pode ser considerada um procedimento não-metodológico de produção de conhecimento, mas que utiliza a imaginação como recurso heurístico. No caso específico, como Feynman (1993) destaca, tal investigação relacionava-se com os fundamentos da Eletrodinâmica Quântica:

Prossegui tentando obter as equações das vibrações. Então pensei sobre como os elétrons começam a mover-se nas suas órbitas na relatividade. Depois, há a equação de Dirac na eletrodinâmica. E depois a eletrodinâmica quântica. E antes que eu percebesse (demorou muito pouco), eu estava "brincando" - trabalhando, na verdade - com o mesmo velho problema que tanto amava e que eu havia parado de es- 
tudar quando fui para Los Alamos: meus problemas do tipo problema de tese; todas aquelas coisas fora de moda, maravilhosas (FEYNMAN, 1993, p. 168).

Além disso, não significa que porque Feynman não explicitou estar construindo um experimento mental, considerando a imaginação como recurso heurístico para tal construção, que esta não tenha se configurado como um recurso heurístico ativo. $\mathrm{O}$ uso da imaginação como recurso heurístico, em relação com outras concepções próprias de Feynman e da forma como ele buscou abordar o fenômeno, contribuíram para o desenvolvimento científico, apesar deste uso não ser aqui considerado uma "metodologia" utilizada. Visualizar essa contribuição torna-se possível, quando Feynman (1993) acrescenta: “Os diagramas e todo esse negócio pelo qual recebi o prêmio Nobel se originaram dessa brincadeira com o prato vibrante" (FEYNMAN, 1993, p. 168).

Ou seja, não significa que a importância deste episódio possa ser reconhecida somente devido ao fato de que ele tenha contribuído para o desenvolvimento de uma nova subárea da Mecânica Quântica. Ou, ainda, que ele passe a ter validade devido ao Prêmio Nobel, recebido por seu idealizador. No entanto, é importante destacar que o desenvolvimento da Eletrodinâmica Quântica, segundo o próprio Feynman, começou com o despertar da curiosidade através do uso da imaginação, para então esta poder contribuir como um recurso que o auxiliou a criar modelos explicativos e testá-los, visando explicar o fenômeno com o "prato vibrante".

Os diagramas a que Feynman se refere na citação acima consistem em uma ferramenta gráfica para auxiliar no desenvolvimento de constructos teóricos da Eletrodinâmica Quântica. Como mostrado na Fig. 3, extraída de Aguilar (2018), os diagramas de Feynman representam, sem a necessidade de utilizar cálculos, partículas interagindo e os produtos destas interações:

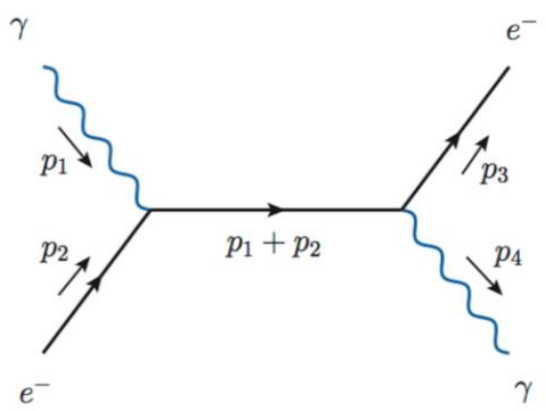

(a)

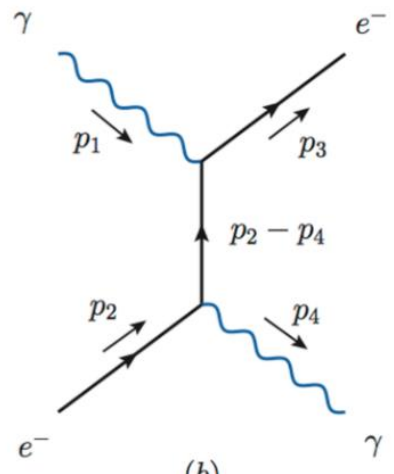

(b)

Fig. 3 - Diagramas de Feynman representando o espalhamento Compton (Extraído e adaptado de AGUILAR, 2018, p. 4205-7). 
Neste caso específico da Fig. 3, o diagrama de Feynman está representando de duas formas ( $\mathrm{a}$ e b) o efeito Compton, destacando a interação de um fóton (representado por $\gamma$ ) e de um elétron (representado por $e-$ ), de modo que, portanto, do lado esquerdo, apresentamse as partículas iniciais que interagem para, no final, ser possível detectar as que aparecem do lado direito; as partículas finais. Desse modo:

No diagrama (a) um elétron real e um fóton são combinados, criando um elétron virtual (representado pela linha interna) cuja massa e energia são diferentes do elétron que aparece no estado inicial. Este elétron virtual, devido as suas massa e energia não realística, emite um fóton e um elétron que definem as partículas que compõem o estado final. Já no diagrama (b) o elétron emite um fóton e depois é espalhado pelo fóton inicial (AGUILAR, 2018, p. 4205-7).

Ainda que essa breve caracterização não intencione fornecer um amplo estudo do que são os diagramas de Feynman, destaca-se a importância deles para o desenvolvimento da Física. Mesmo que Feynman não estivesse pensando nos diagramas naquele momento, a "brincadeira com o prato" contribui para desenvolvê-los. Nessa perspectiva, ainda, a utilização dos diagramas de Feynman pode ser justificada pela “(...) sua simplicidade de transmitir um conceito físico, sem a necessidade de se enveredar em uma série de cálculos complexos que estes diagramas escondem" (AGUILAR, 2018, p. 4205-1).

Cabe a reflexão, nesse sentido, de buscar compreender e desenvolver atividades que divirtam, que envolvam os estudantes, proporcionando e incentivando o uso da imaginação. Assim, pensar propostas de ensino que visem trabalhar a imaginação de forma lúdica, por exemplo, pode ser uma forma que ainda deva ser mais explorada em futuras pesquisas envolvendo educação científica. Nesse sentido, faz-se pertinente buscar desenvolver materiais, cursos, e diversas ferramentas que, aliadas à História da Física e à Filosofia da Ciência, busquem uma formação inicial dos futuros professores que discuta o papel da imaginação no desenvolvimento de experimentos mentais e suas contribuições para o desenvolvimento da Física.

Dessa forma, ainda tratando de Feynman e a imaginação como recurso heurístico, este reconheceu, em seu discurso ao ser laureado com o Nobel em 1965, a importância que a imaginação desempenhou nesse processo. Nas palavras de Feynman:

A imaginação se estende repetidamente tentando alcançar algum nível mais alto de compreensão, até que de repente me vejo momentaneamente sozinho antes que um novo canto do padrão de beleza e verdadeira majestade da natureza seja revelado (FEYNMAN, 1965, tradução do autor).

Dessa forma, torna-se importante destacar aspectos que envolvam a imaginação no desenvolvimento científico, a fim de superar uma concepção rígida e robótica, de um cientista enquanto máquina de acentuada nolição, cujas observações são neutras e os aspectos psicológicos, inexistentes. 
Tais aspectos, tanto na educação básica quanto na formação de professores, contribuem para tentar dirimir a concepção indutivista da atividade científica, desmistificando a visão de uma ciência puramente objetiva, de crescimento linearmente acumulativo, neutra e desenvolvida por seres dotados de onisciência incomparável:

Atividades dessa natureza ocupam a mente e revelam quais as crenças dos estudantes sobre um determinado conceito que está sendo investigado. Para alguns estudantes, esta forma de experimento poderá se mostrar óbvia, enquanto que outros irão conjecturar os resultados de uma maneira não usual, por exemplo, fazendo associações (KIOURANIS; SOUZA; SANTIN FILHO, 2010, p. 1507-6).

Dessa maneira, faz-se importante ressaltar, principalmente na educação básica e na formação de professores, a relevância destes aspectos - volitivos frente à falácia de uma suposta nolição - que fazem parte da atividade científica. Nesse sentido, explicitar a importância da imaginação e dos experimentos mentais nos processos sociais e históricos de construção do conhecimento científico torna-se uma perspectiva producente a ser explorada.

\section{Considerações finais}

A proposta de discutir, no ensino de Física, através dos experimentos mentais, o uso da imaginação como um recurso heurístico que contribui na construção do conhecimento científico não tenciona promover uma substituição irredutível de recursos didáticos na prática do professor. De fato, a discussão que se objetiva é de, através da abordagem histórica da importância desses experimentos mentais, promover uma discussão crítica acerca da NdC. Tal discussão pode envolver, por exemplo, a imagem que se constrói do cientista e os processos sociais e culturais de construção de conhecimento, em vez de simplesmente agir de forma rija e reducionista, ao ensinar apenas os resultados da atividade científica.

Além da possibilidade de discutir a imagem que se constrói do cientista, tratar a imaginação e suas relações com experimentos mentais pode contribuir para trabalhar aspectos de $\mathrm{NdC}$ relacionados à serendipidade, por exemplo. Nessa perspectiva, tratando a serendipidade, o professor pode discutir com os alunos a estrutura das "descobertas" científicas, utilizando como exemplo experimentos mentais para poder ilustrar que tais "descobertas" não são assim tão acidentais, como muitas vezes a atividade científica é popularmente divulgada. A atividade científica, assim como todas as atividades humanas, possui intencionalidades e não pode ser reduzida a uma sucessão de eventos acidentais que supostamente culminaram em grandes feitos científicos.

Nessa perspectiva de considerar o ensino de Física a partir dos papéis da imaginação, vale destacar que, tratando destes como recursos heurísticos, torna-se interessante compreendê-los não necessariamente em um local repetidamente privilegiado no desenvolvimento de uma conjectura. Diferentemente, é importante compreendê-los presentes em momentos atípicos desse processo. Essa compreensão se faz útil quando destaca que tratar estes experimentos 
mentais como sempre presentes em uma "etapa" do desenvolvimento da ciência, é pensar tal atividade científica em uma marcha rígida de etapas que supostamente deveriam ser seguidas de forma canônica, o que levaria novamente ao problema da compreensão estritamente indutiva de ciência. Assim, este artigo teve o objetivo de discutir a imaginação como um recurso heurístico pensando nas contribuições destas para o desenvolvimento de experimentos mentais, o que não significa, como salientado, que sempre que a imaginação for empregada como um recurso heurístico esta precise ser utilizada para o desenvolvimento de experimentos mentais, tampouco que só neste molde ela seria um recurso ativo no desenvolvimento científico.

Dessa forma, discutir as possibilidades e limites de pensar propostas didáticas (ou materiais) que envolvam e discutam a imaginação na ciência, contribui para trabalhar aspectos relacionados com Natureza da Ciência. Nesse sentido, cabe ressaltar a importância de discutir que "Saber a ciência (o conteúdo científico) é condição necessária, e indispensável, mas não

suficiente para saber sobre a ciência, sobre a natureza do empreendimento científico. É imperativo uma educação 'em' e 'sobre' a ciência” (PEDUZZI; RAICIK, 2017, p. 7, grifos meus). Desta forma, uma das maneiras para que se promova um ensino em e sobre a ciência, tanto na educação básica quanto na superior, é discutir aspectos relacionados à Natureza da Ciência como condição sine qua non, e não como somente (mais) uma forma de abordar a atividade científica.

O apelo que sugere tratar aspectos relacionados à Natureza da Ciência no ensino de ciências se deve, nesse sentido, à necessidade de superar (ou ao menos dirimir) as concepções distorcidas da atividade científica. Relacionar a importância da imaginação como um recurso heurístico ativo nos processos de construção de conhecimento científico não deve ser feito sem a contextualização histórica de episódios. Tal contextualização pode ser feita utilizando experimentos mentais, por exemplo, destacando como estes contribuíram para o desenvolvimento científico naquele episódio histórico específico. Ressalta-se, nessa perspectiva, que tal contextualização histórica, visando um ensino em e sobre a ciência, deve considerar as discussões da moderna filosofia da ciência, muitas vezes sintetizadas nos trabalhos que envolvem a Natureza da Ciência.

Torna-se importante, portanto, perceber as possibilidades de compreender o uso da imaginação no ensino de Física como um recurso heurístico - seja através da discussão dos experimentos mentais, seja de outras formas - mas também como uma ferramenta didática. Trabalhar a imaginação pode estar relacionado com propostas de mediar, em sala de aula, o desenvolvimento de uma argumentação crítica com os estudantes, visto que essa, tanto enfatizando os êxitos quanto as limitações, contribui para nos afastarmos da concepção distorcida (ou empirista ingênua) da figura do cientista e da atividade científica de uma forma geral.

\section{Agradecimentos}

O autor agradece à Coordenação de Aperfeiçoamento de Pessoa de Nível Superior (CAPES) através do Programa de Excelência Acadêmica (PROEX) pelo apoio financeiro por 
meio da concessão de bolsa de estudos para Pós-Graduação, bem como o povo brasileiro representado nestes órgãos de fomento à pesquisa.

\section{Referências bibliográficas}

AGUILAR, A. C. Diagramas de Feynman: O poder de uma imagem. Revista Brasileira de Ensino de Física, v. 40, n. 4, 2018.

ARTHURY, L. H. M. A cosmologia moderna à luz dos elementos da epistemologia de Lakatos. Dissertação (Mestrado) - Programa de Pós-Graduação em Educação Científica e Tecnológica (PPGECT), Universidade Federal de Santa Catarina (UFSC), 2010.

CHALMERS, A. O que é Ciência afinal? São Paulo, Editora Brasiliense, 1993.

DAMASIO, F.; PEDUZZI, L. O. Q. História e Filosofia da Ciência na educação científica: para quê? Revista Ensaio - Pesquisa em Educação em Ciências, v.19, 2017.

FEYNMAN, R. P. O Senhor está brincando Sr. Feynman? As estranhas aventuras de um físico excêntrico. Editora Campus, 1993.

FEYNMAN, R. P. Richard P. Feynman - Banquet Speech. Nobelprize.org., Nobel Media AB, 2014. Disponível em:

<https://www.nobelprize.org/nobel_prizes/physics/laureates/1965/feynman-speech.html>.

HANSON, N. R. Observação e Interpretação. In: MORGENBESSER, S. (Org.) Filosofia da Ciência. São Paulo: Editora Cultrix, 1975.

HARRES, J. B. S. Uma revisão de pesquisas nas concepções de professores sobre a natureza da ciência e suas implicações para o ensino. Investigações Ensino de Ciências, v. 4, 1999.

HOLTON, G. The Scientific Imagination: Case Studies. Cambridge University Press, 1978. ISAACSON, W. Einstein: sua vida, seu universo. São Paulo, Companhia das Letras, 2007.

KIOURANIS, N.; SOUZA, A.; FILHO, O. S. Experimentos mentais e suas potencialidades didáticas. Revista Brasileira de Ensino de Física, v. 32, n. 1, 2010.

KÖHNLEIN, J.; PEDUZZI, L. O. Q. Uma discussão sobre a natureza da ciência no ensino médio: um exemplo com a teoria da relatividade restrita. Caderno Brasileiro de Ensino de Física, v. 22, 2005.

LAKATOS, I. O falseamento e a metodologia dos programas de pesquisa científica. In: LAKATOS, I.; MUSGRAVE, A. (Org.) A crítica e o desenvolvimento do conhecimento. São Paulo: Editora Cultrix, 1979. 
MATTHEWS, M. R. História, filosofia e ensino de ciências: a tendência atual de reaproximação. Caderno Catarinense de Ensino de Física, v. 12, n. 3, 1995.

MEHRA, J. The beat of different drum: the life and the Science of Richard Feynman. Oxford University Press, 1996.

MOURA, B. A. O que é Natureza da Ciência e qual sua relação com a História e Filosofia da Ciência? Revista Brasileira de História da Ciência, v. 7, n. 1, Rio de Janeiro, 2014.

OKI, M. C. M.; MORADILLO, E. F. O ensino de história da química: contribuindo para a compreensão da natureza da ciência. Revista Ciência \& Educação, v. 14, 2008.

PEDUZZI, L. O. Q.; SILVEIRA, F. L. Três episódios da descoberta científica: da caricatura empirista a uma outra história. Caderno Brasileiro de Ensino de Física, v. 23, 2006.

PEDUZZI, L. O. Q.; RAICIK, A. C. Sobre a natureza da ciência: asserções comentadas para uma articulação com a história da ciência. Florianópolis: Universidade Federal de Santa Catarina, 2019. Disponível em: <www.evolucaodosconceitosdafisica.ufsc.br〉.

POPPER, K. R. A lógica da pesquisa científica. São Paulo, Editora Cultrix, 1972.

RAICIK, A. C.; PEDUZZI, L. O. Q.; ANGOTTI, J. A. P. Experimentos exploratórios e experientia literata: (re) pensando a experimentação. Investigações em Ensino de Ciências, v. 23, n. 1, 2018.

SILVEIRA, F. L. A metodologia dos programas de pesquisa: a epistemologia de Imre Lakatos. Caderno Brasileiro de Ensino de Física, n. 13, v. 3, 1996.

TULEJA, S.; GAZOVIC, B.; TOMORI, A. Feynman's wobbling plate. American Journal of Physics, v. 75, n. 3, 2007. 